\title{
The study of brain functional connectivity in Parkinson's disease
}

\author{
Lin-lin Gao ${ }^{1,2}$ and Tao Wu ${ }^{1,2^{*}}$
}

\begin{abstract}
Parkinson's disease (PD) is a neurodegenerative disorder primarily affecting the aging population. The neurophysiological mechanisms underlying parkinsonian symptoms remain unclear. PD affects extensive neural networks and a more thorough understanding of network disruption will help bridge the gap between known pathological changes and observed clinical presentations in PD. Development of neuroimaging techniques, especially functional magnetic resonance imaging, allows for detection of the functional connectivity of neural networks in patients with PD. This review aims to provide an overview of current research involving functional network disruption in PD relating to motor and non-motor symptoms. Investigations into functional network connectivity will further our understanding of the mechanisms underlying the effectiveness of clinical interventions, such as levodopa and deep brain stimulation treatment. In addition, identification of PD-specific neural network patterns has the potential to aid in the development of a definitive diagnosis of PD.
\end{abstract}

Keywords: Parkinson's disease, Functional connectivity, fMRI

\section{Background}

Parkinson's disease (PD) is the second most common neurodegenerative disorder in the aging population. PD is characterized by progressive deterioration of motor function, such as bradykinesia, rigidity, resting tremor, gait disturbance, and postural instability. Patients with PD also experience non-motor symptoms such as cognitive deficits, anxiety, apathy, hallucination, and depression. The pathological hallmark of PD is progressive decrease in dopamine concentrations and neuronal cell loss within the substantia nigra and other brain structures combined with the appearance of intracytoplasmic inclusions composed of $\alpha$-synuclein aggregates known as Lewy bodies [1]. However, the precise mechanism by which the pathological changes in the brain result in the described clinical symptoms is unknown. It is well known that PD affects a large scale of neural networks. For example, dysfunction of cortico-basal gangliathalamo-cortical pathway is well known to be critical for the development of parkinsonian symptoms [2].

\footnotetext{
*Correspondence: wutao69@gmail.com

'Department of Neurobiology, Key Laboratory on Neurodegenerative Disorders of Ministry of Education, Beijing Institute of Geriatrics, Xuanwu Hospital, Capital Medical University, Beijing 100053, China

Beijing Key Laboratory on Parkinson's Disease, Parkinson Disease Center of Beijing Institute for Brain Disorders, Beijing, China
}

Therefore, further examination of neuronal network integrity may provide more valuable information for understanding the pathophysiological changes of PD than investigations of local brain activity, and may be helpful to bridge the gap between pathological changes and clinical presentations in PD.

The development of techniques such as functional magnetic resonance imaging (fMRI), electroencephalography (EEG), magnetoencephalography MEG), and transcranial magnetic stimulation (TMS) has greatly enhanced the ability to evaluate functional network integrity in vivo $[3,4]$. In recent years, extensive studies have investigated PD-related disruption of functional networks, and have provided useful information regarding neurophysiological mechanisms underlying parkinsonian symptoms. In addition, these studies have served to identify mechanisms of anti-parkinsonian interventions, and suggest that brain networks have the potential to be developed as a biomarker for the diagnosis of PD. The aim of this review is to provide a comprehensive overview of the application of functional network connectivity in investigating neural mechanisms underlying parkinsonian symptoms and interventions, and as a potential biomarker in patients with PD. The reviewed publications were selected by the authors on the basis of relevance to the 
topic. The functional connectivity studies included in the current study is summarized in Table 1.

\section{Techniques to assess network integrity}

EEG, fMRI, and MEG are the most widely used techniques that enable researchers to assess large-scale neural networks at different spatial and temporal resolutions. With the advantages of being noninvasive and having high spatial resolution, fMRI is now the most used method to investigate functional integrity of networks in PD. In broad definition, fMRI includes all magnetic resonance imaging (MRI) methods that detect neural functional changes, such as blood oxygen leveldependent (BOLD) contrast imaging, perfusion, or diffusion. However, fMRI typically refers to BOLD fMRI, which detects changes in oxygen saturation levels of the blood [5]. In this review, the applications of BOLD fMRI on network integrity in PD will be discussed. The methods used to explore network integration involve the analysis of functional or effective connectivity [6-10]. Functional connectivity is defined as a temporal correlation between spatially remote neurophysiological events, whereas effective connectivity is defined as the influence that one neuronal system exerts over another [11]. Findings from both methods will be presented in this review.

\section{Motor symptoms-related network changes Bradykinesia}

Bradykinesia is an important feature contributing to motor difficulties in PD. In this review, we use bradykinesia to describe bradykinesia (slowness of movement), hypokinesia (smallness of movement), and akinesia (lack of movement). Although extensive research has been conducted in this area, the pathophysiological mechanisms underlying bradykinesia remain unclear. Several neuroimaging studies have investigated network connectivity during performance of various motor tasks in patients with PD. During the performance of selfinitiated movement, the functional connectivity between the striatum and cortical motor areas, i.e., primary motor cortex (M1), premotor cortex (PMC), and supplementary motor area (SMA), is weakened in PD [12]. In addition, the connectivity between the prefrontal cortex, PMC and SMA is disrupted [12-15]. The SMA is critical in planning and decision of movements and plays a primary role in the preparation of self-initiated movements [16-18]. The SMA is one of the main receiving regions of the basal ganglia motor circuit [19]. The dysfunction of the SMA has been correlated with motor difficulty, and the administration of levodopa has been shown to relatively normalize the function of the SMA in patients with PD resulting in improved motor performance $[20,21]$. Thus, the disconnection of the striato-SMA pathway due to the deficit of the nigrostriatal dopamine system is likely to be an important factor contributing to bradykinesia in PD.

Motor automaticity has been proposed as a possible mechanism underlying bradykinesia [22]. Automaticity is the ability to perform movements without attention directed toward the details of the movement [23]. In healthy people, the processing of motor automaticity is accompanied by the more efficiency of neural network and less significant of attentional network. The automated motor program is likely stored in the sensorimotor striatum (posterior putamen), and is resistant to interference [22, 24-26]. Most bradykinesia-related motor problems are associated with deterioration of motor automaticity, as PD patients tend to perform all daily behaviors slower or with smaller amplitude, e.g., akinesia, reduced arm swing, freezing of gait (FOG), and micrographia [27]. Motor automaticity dysfunction is already apparent in the early stages of PD [28, 29]. During automatic processing, the connectivity of striatocortical motor pathways is decreased, the activity in the sensorimotor striatum is not enhanced, and the attentional networks remain active in PD compared to controls $[22,29,30]$.

Based on these studies of neural networks, neural mechanisms for impaired motor automaticity in PD includes less efficient neural coding of movement, failure to shift automated motor skills to the sensorimotor striatum, instability of the automatic mode within the striatum, and use of attentional control efforts to execute movements usually performed automatically in healthy people [22]. As a consequence, PD patients lose previously acquired automatic skills and have difficulty in acquiring new automatic skills or restoring lost motor skills, which results in bradykinesia.

\section{Tremor}

As tremor may disturb fMRI signals, tremor-related network connectivity has been much less investigated compared to bradykineisa. In an elegant study, Helmich and colleagues described the use of electromyography to monitor tremor during fMRI scanning, and measured functional connectivity between basal ganglia nuclei and the cerebellothalamic circuit [31]. The authors reported that the basal ganglia nuclei were transiently activated at the onset of tremor, while activity in the cerebellothalamic circuit correlated with tremor amplitude. The internal globus pallidus and putamen had increased functional connectivity with the cerebellothalamic circuit. These findings suggest that parkinsonian tremor may result from a pathological interaction between the basal ganglia and the cerebellothalamic circuit, which is supported by the following studies [30].

Functional connectivity experiments have also been used to explore the underlying mechanisms for several 
Table 1 Summary of the characteristics of the reviewed studies

\begin{tabular}{|c|c|c|c|c|}
\hline Paper & Number of patients & Task & Type of connectivity & Main findings \\
\hline \multirow{2}{*}{$\begin{array}{l}\text { Wu T et al., } \\
2011[12]\end{array}$} & 18 PD patients & \multirow{2}{*}{$\begin{array}{l}\text { A self-initiated right } \\
\text { hand tapping task }\end{array}$} & \multirow{2}{*}{$\begin{array}{l}\text { Effective connectivity } \\
\text { psychophysiological } \\
\text { interaction (PPI) }\end{array}$} & \multirow{2}{*}{$\begin{array}{l}\text { The striatum-cortical connections were } \\
\text { weakened, while the cortico-cerebellar } \\
\text { connections were strengthened in PD }\end{array}$} \\
\hline & 18 controls & & & \\
\hline \multirow{2}{*}{$\begin{array}{l}\text { Rowe J et al., } \\
2002[13]\end{array}$} & 12 PD patients & \multirow{2}{*}{$\begin{array}{l}\text { An overlearned motor } \\
\text { sequence task, with } \\
\text { and without attention }\end{array}$} & \multirow{2}{*}{$\begin{array}{l}\text { Effective connectivity } \\
\text { - Structural equation } \\
\text { modeling (SEM) }\end{array}$} & \multirow{2}{*}{$\begin{array}{l}\text { Attention to action did not increase } \\
\text { the connectivity between the prefrontal } \\
\text { cortex, lateral premotor cortex and SMA } \\
\text { in PD }\end{array}$} \\
\hline & 12 controls & & & \\
\hline \multirow{2}{*}{$\begin{array}{l}\text { Wu T et al., } \\
2010 \text { [14] }\end{array}$} & 12 patients & \multirow{2}{*}{$\begin{array}{l}\text { two sequences of right } \\
\text { hand finger tapping }\end{array}$} & \multirow{2}{*}{$\begin{array}{l}\text { Effective connectivity } \\
\text { psychophysiological } \\
\text { interaction (PPI) }\end{array}$} & \multirow{2}{*}{$\begin{array}{l}\text { The pre-SMA, cerebellum, and cingulate } \\
\text { motor area had increased effective } \\
\text { connectivity with brain networks in PD }\end{array}$} \\
\hline & $\begin{array}{l}12 \text { age-and sex-matched } \\
\text { healthy subjects }\end{array}$ & & & \\
\hline \multirow{2}{*}{$\begin{array}{l}\text { Rowe JB et al., } \\
2010 \text { [15] }\end{array}$} & 16 PD patients & \multirow{2}{*}{$\begin{array}{l}\text { A visually paced } \\
\text { finger-tapping task }\end{array}$} & \multirow{2}{*}{$\begin{array}{l}\text { Effective connectivity } \\
\text { Dynamic causal modelling } \\
\text { (DCM) }\end{array}$} & \multirow{2}{*}{$\begin{array}{l}\text { The coupling between the prefrontal } \\
\text { cortex and the pre-SMA was enhanced } \\
\text { in PD }\end{array}$} \\
\hline & 42 controls & & & \\
\hline \multirow{2}{*}{$\begin{array}{l}\text { Wu T et al., } \\
2016 \text { [27] }\end{array}$} & 36 PD patients & \multirow[t]{2}{*}{ Handwriting } & \multirow[t]{2}{*}{ Functional connectivity } & \multirow{2}{*}{$\begin{array}{l}\text { Dysfunction of basal ganglia motor } \\
\text { circuit in both consistent and progressive. } \\
\text { Progressive micrographia was also } \\
\text { associated with disconnections between } \\
\text { the pre-SMA, rostral cingulated motor } \\
\text { area and cerebellum }\end{array}$} \\
\hline & 18 controls & & & \\
\hline \multirow{2}{*}{$\begin{array}{l}\text { Wu T et al., } \\
2015[22,29]\end{array}$} & 22 PD patients & \multirow{2}{*}{$\begin{array}{l}\text { Visuomotor } \\
\text { association task }\end{array}$} & \multirow{2}{*}{$\begin{array}{l}\text { Effective connectivity } \\
\text { Granger causality analysis } \\
\text { (GCA) }\end{array}$} & \multirow{2}{*}{$\begin{array}{l}\text { The connectivity from the putamen to } \\
\text { the motor cortex was decreased in PD }\end{array}$} \\
\hline & 22 controls & & & \\
\hline \multirow{2}{*}{$\begin{array}{l}\text { Ma H et al., } \\
2015 \text { [30] }\end{array}$} & 50 PD patients & \multirow[t]{2}{*}{ Resting state } & \multirow[t]{2}{*}{ Functional connectivity } & \multirow{2}{*}{$\begin{array}{l}\text { The bilateral dentate nucleus had higher } \\
\text { connectivity with the bilateral cerebellar } \\
\text { anterior lobe, and lower connectivity with } \\
\text { the bilateral prefrontal cortex in tremor- } \\
\text { dominant PD }\end{array}$} \\
\hline & $\begin{array}{l}29 \text { age-matched health } \\
\text { controls }\end{array}$ & & & \\
\hline \multirow{2}{*}{$\begin{array}{l}\text { Tessitore A } \\
\text { et al., } 2012 \text { [32] }\end{array}$} & 29 PD patients & \multirow[t]{2}{*}{ Resting state } & \multirow[t]{2}{*}{ Functional connectivity } & \multirow{2}{*}{$\begin{array}{l}\text { Reduced connectivity within both } \\
\text { executive-attention and visual networks }\end{array}$} \\
\hline & 15 controls & & & \\
\hline \multirow{2}{*}{$\begin{array}{l}\text { Liu } \mathrm{H} \text { et al., } \\
2013[34]\end{array}$} & 9 PD patients & \multirow[t]{2}{*}{ Resting state } & \multirow[t]{2}{*}{ Functional connectivity } & \multirow{2}{*}{$\begin{array}{l}\text { Decreased connectivity of the dentate } \\
\text { nucleus with the bilateral cerebellar } \\
\text { posterior lobe in tremor-dominant PD }\end{array}$} \\
\hline & 9 controls & & & \\
\hline $\begin{array}{l}\text { Hu X et al., } \\
2015[35,43]\end{array}$ & $\begin{array}{l}21 \text { tremor-dominant } \\
\text { (TD)-PD }\end{array}$ & Resting state & $\begin{array}{l}\text { Voxel-mirrored homotopic } \\
\text { connectivity (VMHC) }\end{array}$ & $\begin{array}{l}\text { TD-PD exhibited significantly lower } \\
\text { VMHC values in the posterior lobe of }\end{array}$ \\
\hline & $\begin{array}{l}29 \text { akinetic-rigid (AR)-PD } \\
\text { patients }\end{array}$ & & & $\begin{array}{l}\text { the cerebellum. AR-PD exhibited lower } \\
\text { VMHC values in the precentral gyrus. }\end{array}$ \\
\hline
\end{tabular}

seibert TM

et al., 2012 [36]

Gorges $\mathrm{M}$ et al., $\quad 14$ cognitively unimpaired 2015 [37] $\quad$ PD patients, 17 cognitively impaired PD patients

\section{2 controls}

Disbrow EA

et al., 2014 [38]

Manza P et al., 2016 [41]
19 cognitively unimpaired controls, 19 cognitively unimpaired PD patients,

18 patients with dementia

14 non-demented PD patients, 20 controls.

Resting state

Resting state

Resting state

62 early-stage PD patients
Functional connectivity

Functional connectivity

Functional connectivity

Functional connectivity

Decreased striato-prefrontal connectivity in patients with dementia

Decreased default mode network connectivity in cognitively impaired PD patients.

Decreased default mode network connectivity in PD

Motor deficit was associated with weaker coupling between anterior putamen and midbrain, cognitive impairment was associated with stronger coupling between the dorsal caudate and the rostral anterior cingulate cortex

Reduced connectivity in the prefrontallimbic network in the depression group depression, 30 PD patients without depression, 30 controls 
Table 1 Summary of the characteristics of the reviewed studies (Continued)

\begin{tabular}{|c|c|c|c|c|}
\hline $\begin{array}{l}\text { Hu X et al., } \\
2015[35,43]\end{array}$ & $\begin{array}{l}20 \text { depressed PD patients, } \\
40 \text { non-depressed PD } \\
\text { patients, } 43 \text { controls }\end{array}$ & Resting state & Functional connectivity & $\begin{array}{l}\text { Stronger connectivity between the left } \\
\text { median cingulate cortex and default } \\
\text { mode network in the depressed PD }\end{array}$ \\
\hline $\begin{array}{l}\text { Sunwoo MK et al., } \\
2015 \text { [46] }\end{array}$ & $\begin{array}{l}110 \text { PD patients subdivided } \\
\text { into three groups based } \\
\text { on olfactory performance }\end{array}$ & Resting state & Functional connectivity & $\begin{array}{l}\text { Enhancement of striatocortical connectivity } \\
\text { in the bilateral occipital areas and right } \\
\text { frontal areas in patients with olfactory } \\
\text { impairment }\end{array}$ \\
\hline $\begin{array}{l}\text { Baggio HC et al., } \\
2015 \text { [47] }\end{array}$ & 62 PD patients, 31 controls & Resting state & Functional connectivity & $\begin{array}{l}\text { Reduced connectivity in left-sided circuits, } \\
\text { predominantly involving limbic, striatal } \\
\text { and frontal territories in apathetic PD } \\
\text { patients }\end{array}$ \\
\hline $\begin{array}{l}\text { Yao N et al., } \\
2015 \text { [48] }\end{array}$ & $\begin{array}{l}12 \text { PD patients without } \\
\text { hallucinations, } 12 \text { PD } \\
\text { patients with visual } \\
\text { hallucinations, } 14 \text { controls }\end{array}$ & Resting state & Functional connectivity & $\begin{array}{l}\text { Increased occipital-corticostriatal } \\
\text { connectivity in PD patients with visual } \\
\text { hallucinations }\end{array}$ \\
\hline $\begin{array}{l}\text { Kwak Y et al., } \\
2010[50]\end{array}$ & $\begin{array}{l}24 \text { mild to moderate stage } \\
\text { PD patients, } 24 \text { controls }\end{array}$ & Resting state & Functional connectivity & $\begin{array}{l}\text { Increased cortico-striatal connectivity in } \\
\text { PD patients }\end{array}$ \\
\hline $\begin{array}{l}\text { Agosta F et al., } \\
2014[51]\end{array}$ & $\begin{array}{l}69 \text { PD patients, } 25 \text { drug- } \\
\text { naïve, } 44 \text { dopamine treated, } \\
27 \text { controls }\end{array}$ & Resting state & Functional connectivity & $\begin{array}{l}\text { Decreased striato-thalamic connectivity, } \\
\text { increased striato-temporal, and thalamo- } \\
\text { cortical connections in dopaminergic } \\
\text { treated PD }\end{array}$ \\
\hline $\begin{array}{l}\text { Bell PT et al., } \\
2015[52]\end{array}$ & 39 PD patients, controls & Resting state & Functional connectivity & $\begin{array}{l}\text { Decoupling between the striatum and } \\
\text { thalamic and sensorimotor networks } \\
\text { in PD }\end{array}$ \\
\hline $\begin{array}{l}\text { Szewczyk-Krolikowski } \\
\text { K et al., } 2014 \text { [53] }\end{array}$ & 19 PD patients, 19 controls & Resting state & Functional connectivity & $\begin{array}{l}\text { Reduced basal ganglia network } \\
\text { connectivity in PD }\end{array}$ \\
\hline $\begin{array}{l}\text { Herz DM et al., } \\
2015[54]\end{array}$ & 26 PD patients & $\begin{array}{l}\text { Visually cued } \\
\text { movement }\end{array}$ & $\begin{array}{l}\text { Effective connectivity } \\
\text { Dynamic causal } \\
\text { modelling (DCM) }\end{array}$ & $\begin{array}{l}\text { Increase in the putamen and primary } \\
\text { motor cortex connectivity after levodopa } \\
\text { intake during movement suppression in } \\
\text { patients who later developed levodopa- } \\
\text { induced dyskinesias }\end{array}$ \\
\hline $\begin{array}{l}\text { Herz DM et al., } \\
2016[55]\end{array}$ & $\begin{array}{l}12 \text { PD patients with } \\
\text { dyskinesias, } 12 \text { patients } \\
\text { without dyskinesias }\end{array}$ & Resting state & Functional connectivity & $\begin{array}{l}\text { Increased connectivity between the } \\
\text { primary sensorimotor cortex and } \\
\text { putamen after levodopa intake in } \\
\text { patients with dyskinesias }\end{array}$ \\
\hline $\begin{array}{l}\text { Kahan J et al., } \\
2014 \text { [57] }\end{array}$ & 12 PD patients & Resting state & $\begin{array}{l}\text { Effective connectivity } \\
\text { Dynamic causal } \\
\text { modelling (DCM) }\end{array}$ & $\begin{array}{l}\text { The strength of effective subthalamic } \\
\text { nucleus afferents and efferents were } \\
\text { reducedm cortico-striatal, thalamo- } \\
\text { cortical and direct pathways were } \\
\text { strengthened by DBS }\end{array}$ \\
\hline $\begin{array}{l}\text { Schweder PM et al., } \\
2010 \text { [58] }\end{array}$ & 1 PD patient & Resting state & Functional connectivity & $\begin{array}{l}\text { Normalization of pathological } \\
\text { pedunculopontine nucleus (PPN) } \\
\text { connectivity after PPN-DBS }\end{array}$ \\
\hline $\begin{array}{l}\text { Long D et al., } \\
2012 \text { [59] }\end{array}$ & $\begin{array}{l}19 \text { early PD patients, } \\
27 \text { controls }\end{array}$ & Resting state & $\begin{array}{l}\text { RFCS (regional functional } \\
\text { connectivity strength) }\end{array}$ & $\begin{array}{l}\text { The PD patients showed significant } \\
\text { RFCS increases in the left } \\
\text { parahippocampal gyrus, left angular } \\
\text { gyrus and right middle temporal gyrus }\end{array}$ \\
\hline
\end{tabular}

other parkinsonian motor symptoms. For example, Tessitore and colleagues reported that PD patients with FoG had impaired functional connectivity within the frontoparietal networks sub-serving attentional functions [32]. Functional neuroimaging studies suggest that the disturbances in frontal cortical regions, the basal ganglia, and the midbrain locomotor region are possibly the origins of FoG [33]. Network connectivity also can be used to identify the neural characters in different subtypes of PD $[2,34,35]$.

\section{Non-motor symptoms}

In addition to symptoms related to motor function, most PD patients present with some non-motor symptoms such as cognitive, emotional, or olfactory impairments. In recent years, more focus has been applied to characterizing the neural network of these non-motor symptoms. Cognitive deficits are common in PD patients. PD with dementia is associated with selective disruption of corticostriatal connectivity [36]. Moreover, it has been shown that the connectivity of the so called "default 
mode network" (DMN) is disrupted in PD patients with cognitive deficits $[37,38]$. The DMN is a network showing consistent task-related deactivations, and includes the medial prefrontal cortex, anterior cingulate cortex, posterior cingulate cortex, precuneus, and inferior parietal lobe [39, 40]. The DMN is thought to facilitate cognitive performance by allocating neural resources to critical brain regions. The disruption of the DMN was associated with the progress of cognitive decline [37], while the decline in cognitive function, particularly in the memory and visuospatial domains, was associated with stronger coupling between the dorsal caudate and the rostral anterior cingulate cortex [41]. These findings suggest that malfunctioning of the DMN may contribute to the executive function deficits in PD.

Depression is the most frequent psychiatric disorder reported in patients with PD. Abnormal prefrontallimbic network connectivity has been demonstrated in depressed PD patients [31, 42]. PD patients with depression are associated with disrupted functional connectivity between the median cingulate cortex and precuneus, prefrontal cortex, and cerebellum [43]. The cingulate cortex plays key roles in integrating multimodal information that is important for emotional, sensorimotor, and cognitive functions [44]. The median cingulate cortex also appears to be involved in many emotion-related cognitive processes such as meditation, self-related rumination, aversive conditioning, and the anticipation and perception of pain [45]. The impaired median cingulate cortex-related networks may play a role in depression experienced by patients with PD.

Network connectivity in some other non-motor symptoms, such as olfactory impairment, apathy, and hallucination has also been investigated. PD patients with olfactory impairment had decreased connectivity between the posterior cingulate cortex and bilateral primary sensory areas, right frontal areas, and right parietal areas, and had an enhancement of striatocortical connectivity compared to PD patients with normal olfaction [46]. Apathetic PD patients showed reduced functional connectivity mainly involving limbic striatal and frontal territories. In addition, the limbic division of the left striatum showed reduced connectivity with the ipsilateral frontal cortex and with the rest of the left striatum [47]. In PD patients with visual hallucinations, occipitalcortico-striatal connectivity was significantly higher than in patients without hallucinations [48]. Hallucinations have been associated with functional abnormalities in primary visual cortex and visual associative cortices [49].

\section{Intervention-related network changes}

Functional connectivity can be also used to investigate neural mechanisms underlying anti-parkinsonian interventions. Levodopa treatment has been reported to normalize the function of the basal ganglia motor pathways (e.g., by enhancing neural activity in the SMA and striatum) and restore striato-cortical motor pathway connectivity $[4,50-53]$ in a manner associated with improvements in motor function.

Although levodopa remains the most effective medication for the management of PD symptoms, many PD patients develop daily fluctuations in mobility and involuntary movements known as levodopa-induced dyskinesias (LID). The neural correlates in the genesis of LID remain poorly understood. A recent study found an increase in connectivity between the putamen and M1 after levodopa intake in patients developed LID [54]. This excessive striato-cortical connectivity in response to levodopa may play a role in the pathophysiology of LID [54, 55]. Another study showed that the connectivity of inferior frontal cortex was decreased with M1 and increased with the putamen in patients with LID [56]. This finding suggests that the neural network centered on the inferior frontal cortex may also involve in the pathophysiological mechanisms underlying LID.

Deep brain stimulation (DBS) is another effective therapy for PD, but the neural mechanism underlying therapeutic effects of DBS remain unclear. It has been shown that DBS on the subthalamic nucleus (STN) can modulate the connectivity of striato-thalamo-cortical and STN-cortical pathways in association with symptom improvements [57]. The pedunculopontine nucleus (PPN) is a target in treating primarily gait and posture symptoms. PPN-DBS has been reported to normalize pathological PPN connectivity [58].

\section{Diagnosis}

The diagnosis of PD is based mainly on clinical assessments. Some studies have combined fMRI and various pattern analysis methods to try to establish an imaging methodology for PD diagnosis [53, 59-61]. In a recent study, the authors of this review have identified a PDrelated spatial covariance pattern that was characterized by decreased activity in the striatum, supplementary motor area, middle frontal gyrus, and occipital cortex, and also by increased activity in the thalamus, cerebellum, precuneus, superior parietal lobule, and temporal cortex. This pattern had a high accuracy $(90 \%)$ to discriminate PD patients from healthy controls [59]. These studies have proven that network connectivity approach can identify characteristic PD-specific neural changes, and has the potential of network pattern as a biomarker for PD diagnosis. However, functional connectivity cannot directly reveal pathological changes in PD, therefore, whether this method can be applied in clinical practice needs further investigation. 


\section{Conclusions}

\section{Future directions}

Studies on functional connectivity have provided important information on PD-related functional and pathophysiological changes. At present, functional connectivity is primarily used to further understand how pathological changes lead to parkinsonian symptoms, and is far from being a method in routine clinical investigations. As shown in the Table 1, the analytic methods of "functional connectivity" studies vary a lot from study to study. Few studies have used the same "functional connectivity" procedure. Therefore, it is hard to perform meta-analysis on these studies. In contrast, voxel-level analysis, like most PET studies and some resting-state fMRI studies focusing the local activity support coordinate-based meta-analysis and, hence, are more helpful to clinical studies. Additional research should focus on increased efforts to develop neural network pattern as a neuroimaging biomarker for early diagnosis of PD; this might well require further technical and methodological improvements. These developments will improve early diagnosis, better evaluate disease progression, differentiate PD from other parkinsonisms on an individual basis, and may guide novel targets for future therapies.

\section{Acknowledgements}

Not applicable.

\section{Funding}

This research did not receive any specific grant from funding agencies in the public, commercial, or not-for-profit sectors.

\section{Availability of data and material}

Not applicable.

\section{Authors' contributions}

L-IG: execution of the research, analysis of the data, writing of the manuscript; TW: conception, organization of the research, and critique of the manuscript. Both authors read and approved the final manuscript.

\section{Competing interests}

Not applicable.

\section{Consent for publication}

Not applicable.

\section{Ethics approval and consent to participate}

Not applicable.

Received: 5 September 2016 Accepted: 20 October 2016

Published online: 28 October 2016

\section{References}

1. Jankovic J. Parkinson's disease: clinical features and diagnosis. J Neurol Neurosurg Psychiatry. 2008;79:368-76

2. DeLong MR, Wichmann T. Circuits and circuit disorders of the basal ganglia. Arch Neurol. 2007:64:20-4.

3. Fox MD, Raichle ME. Spontaneous fluctuations in brain activity observed with functional magnetic resonance imaging. Nat Rev Neurosci. 2007:8:700-11.

4. Wu T, Long X, Zang Y, Wang L, Hallett M, Li K, Chan P. Regional homogeneity changes in patients with Parkinson's disease. Hum Brain Mapp. 2009;30:1502-10.
5. Ogawa S, Lee TM, Kay AR, Tank DW. Brain magnetic resonance imaging with contrast dependent on blood oxygenation. Proc Natl Acad Sci U S A 1990;87:9868-72.

6. Sporns O, Chialvo DR, Kaiser M, Hilgetag CC. Organization, development and function of complex brain networks. Trends Cogn Sci. 2004;8:418-25.

7. Horwitz B. The elusive concept of brain connectivity. Neuroimage. 2003;19: 466-70.

8. Stam CJ. Characterization of anatomical and functional connectivity in the brain: a complex networks perspective. Int J Psychophysiol. 2010;77:186-94.

9. Bullmore E, Sporns O. Complex brain networks: graph theoretical analysis of structural and functional systems. Nat Rev Neurosci. 2009;10:186-98.

10. Stam CJ, Reijneveld JC. Graph theoretical analysis of complex networks in the brain. Nonlinear Biomed Phys. 2007;1:3.

11. Friston K. Functional and effective connectivity in neuroimaging: A synthesis [J]. Hum Brain Mapp. 1994:2:56-78.

12. Wu T, Wang L, Hallett M, Chen Y, Li K, Chan P. Effective connectivity of brain networks during self-initiated movement in Parkinson's disease. Neuroimage. 2011;55:204-15

13. Rowe J, Stephan KE, Friston K, Frackowiak R, Lees A, Passingham R. Attention to action in Parkinson's disease: impaired effective connectivity among frontal cortical regions. Brain. 2002;125:276-89.

14. Wu T, Chan P, Hallett M. Effective connectivity of neural networks in automatic movements in Parkinson's disease. Neuroimage. 2010;49: 2581-7.

15. Rowe JB, Hughes LE, Barker RA, Owen AM. Dynamic causal modelling of effective connectivity from fMRI: are results reproducible and sensitive to Parkinson's disease and its treatment? Neuroimage. 2010;52:1015-26.

16. Deiber MP, Passingham RE, Colebatch JG, Friston KJ, Nixon PD, Frackowiak RS. Cortical areas and the selection of movement: a study with positron emission tomography. Exp Brain Res. 1991;84:393-402.

17. Cunnington R, Windischberger C, Deecke L, Moser E. The preparation and execution of self-initiated and externally-triggered movement: a study of event-related fMRI. Neuroimage. 2002;15:373-85

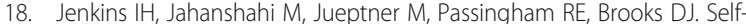
initiated versus externally triggered movements. II. The effect of movement predictability on regional cerebral blood flow. Brain. 2000;123(Pt 6):1216-28.

19. Schell GR, Strick PL. The origin of thalamic inputs to the arcuate premotor and supplementary motor areas. J Neurosci. 1984:4:539-60.

20. Haslinger B, Erhard P, Kampfe N, Boecker H, Rummeny E, Schwaiger M, Conrad B, Ceballos-Baumann AO. Event-related functional magnetic resonance imaging in Parkinson's disease before and after levodopa. Brain. 2001;124:558-70.

21. Buhmann C, Glauche V, Sturenburg HJ, Oechsner M, Weiller C, Buchel C. Pharmacologically modulated fMRI-cortical responsiveness to levodopa in drug-naive hemiparkinsonian patients. Brain. 2003;126:451-61.

22. Wu T, Hallett M, Chan P. Motor automaticity in Parkinson's disease. Neurobiol Dis. 2015:82:226-34

23. Bernstein ME, Hughes FW, Forney RB. The influence of a new chlordiazepoxide analogue on human mental and motor performance. J Clin Pharmacol J New Drugs. 1967;7:330-5

24. Redgrave $P$, Rodriguez $M$, Smith $Y$, Rodriguez-Oroz MC, Lehericy S, Bergman $H$, Agid Y, DeLong MR, Obeso JA. Goal-directed and habitual control in the basal ganglia: implications for Parkinson's disease. Nat Rev Neurosci. 2010;11:760-72.

25. Wu T, Kansaku K, Hallett M. How self-initiated memorized movements become automatic: a functional MRI study. J Neurophysiol. 2004:91:1690-8.

26. Wu T, Hallett M. Neural correlates of dual task performance in patients with Parkinson's disease. J Neurol Neurosurg Psychiatry. 2008;79:760-6.

27. Wu T, Zhang J, Hallett M, Feng T, Hou Y, Chan P. Neural correlates underlying micrographia in Parkinson's disease. Brain. 2016;139:144-60.

28. Wu T, Hallett M. A functional MRI study of automatic movements in patients with Parkinson's disease. Brain. 2005;128:2250-9.

29. Wu T, Liu J, Zhang H, Hallett M, Zheng Z, Chan P. Attention to Automatic Movements in Parkinson's Disease: Modified Automatic Mode in the Striatum. Cereb Cortex. 2015:25:3330-42.

30. Ma H, Chen H, Fang J, Gao L, Ma L, Wu T, Hou Y, Zhang J, Feng T. Restingstate functional connectivity of dentate nucleus is associated with tremor in Parkinson's disease. J Neurol. 2015;262:2247-56.

31. Surdhar I, Gee M, Bouchard T, Coupland N, Malykhin N, Camicioli R. Intact limbic-prefrontal connections and reduced amygdala volumes in Parkinson's disease with mild depressive symptoms. Parkinsonism Relat Disord. 2012;18:809-13. 
32. Tessitore A, Amboni M, Esposito F, Russo A, Picillo M, Marcuccio L, Pellecchia MT, Vitale C, Cirillo M, Tedeschi G, Barone P. Resting-state brain connectivity in patients with Parkinson's disease and freezing of gait. Parkinsonism Relat Disord. 2012:18:781-7.

33. Nutt JG, Bloem BR, Giladi N, Hallett M, Horak FB, Nieuwboer A. Freezing of gait: moving forward on a mysterious clinical phenomenon. Lancet Neurol. 2011;10:734-44.

34. Liu H, Edmiston EK, Fan G, Xu K, Zhao B, Shang X, Wang F. Altered restingstate functional connectivity of the dentate nucleus in Parkinson's disease. Psychiatry Res. 2013;211:64-71.

35. Hu X, Zhang J, Jiang X, Zhou C, Wei L, Yin X, Wu Y, Li J, Zhang Y, Wang J. Decreased interhemispheric functional connectivity in subtypes of Parkinson's disease. J Neurol. 2015;262:760-7.

36. Seibert TM, Murphy EA, Kaestner EJ, Brewer JB. Interregional correlations in Parkinson disease and Parkinson-related dementia with resting functional MR imaging. Radiology. 2012;263:226-34.

37. Gorges M, Muller HP, Lule D, Pinkhardt EH, Ludolph AC, Kassubek J. To rise and to fall: functional connectivity in cognitively normal and cognitively impaired patients with Parkinson's disease. Neurobiol Aging. 2015;36:1727-35.

38. Disbrow EA, Carmichael O, He J, Lanni KE, Dressler EM, Zhang L, MalhadoChang N, Sigvardt KA. Resting state functional connectivity is associated with cognitive dysfunction in non-demented people with Parkinson's disease. J Parkinsons Dis. 2014:4:453-65.

39. Salvador R, Suckling J, Coleman MR, Pickard JD, Menon D, Bullmore E. Neurophysiological architecture of functional magnetic resonance images of human brain. Cereb Cortex. 2005;15:1332-42.

40. Greicius MD, Krasnow B, Reiss AL, Menon V. Functional connectivity in the resting brain: a network analysis of the default mode hypothesis. Proc Natl Acad Sci U S A. 2003;100:253-8.

41. Manza P, Zhang S, Li CS, Leung HC. Resting-state functional connectivity of the striatum in early-stage Parkinson's disease: Cognitive decline and motor symptomatology. Hum Brain Mapp. 2016;37:648-62.

42. Luo C, Chen Q, Song W, Chen K, Guo X, Yang J, Huang X, Gong Q, Shang HF. Resting-state fMRI study on drug-naive patients with Parkinson's disease and with depression. J Neurol Neurosurg Psychiatry. 2014;85:675-83.

43. Hu X, Song X, Li E, Liu J, Yuan Y, Liu W, Liu Y. Altered Resting-State Brain Activity and Connectivity in Depressed Parkinson's Disease. PLoS One. 2015; 10:e131133.

44. Taylor KS, Seminowicz DA, Davis KD. Two systems of resting state connectivity between the insula and cingulate cortex. Hum Brain Mapp. 2009;30:2731-45.

45. Vogt BA, Berger GR, Derbyshire SW. Structural and functional dichotomy of human midcingulate cortex. Eur J Neurosci. 2003;18:3134-44.

46. Sunwoo MK, Cha J, Ham JH, Song SK, Hong JY, Lee JM, Sohn YH, Lee PH. Olfactory performance and resting state functional connectivity in nondemented drug naive patients with Parkinson's disease. Hum Brain Mapp. 2015;36:1716-27.

47. Baggio HC, Segura B, Garrido-Millan JL, Marti MJ, Compta Y, Valldeoriola F, Tolosa $\mathrm{E}$, Junque $\mathrm{C}$. Resting-state frontostriatal functional connectivity in Parkinson's disease-related apathy. Mov Disord. 2015;30:671-9.

48. Yao N, Pang S, Cheung C, Chang RS, Lau KK, Suckling J, Yu K, Mak HK, McAlonan G, Ho SL, Chua SE. Resting activity in visual and corticostriatal pathways in Parkinson's disease with hallucinations. Parkinsonism Relat Disord. 2015;21:131-7.

49. Meppelink AM, de Jong BM, Renken R, Leenders KL, Cornelissen FW, van Laar T. Impaired visual processing preceding image recognition in Parkinson's disease patients with visual hallucinations. Brain. 2009;132:2980-93.

50. Kwak Y, Peltier S, Bohnen NI, Muller ML, Dayalu P, Seidler RD. Altered resting state cortico-striatal connectivity in mild to moderate stage Parkinson's disease. Front Syst Neurosci. 2010;4:143.

51. Agosta F, Caso F, Stankovic I, Inuggi A, Petrovic I, Svetel M, Kostic VS, Filippi M. Cortico-striatal-thalamic network functional connectivity in hemiparkinsonism. Neurobiol Aging. 2014;35:2592-602.

52. Bell PT, Gilat M, O'Callaghan C, Copland DA, Frank MJ, Lewis SJ, Shine JM. Dopaminergic basis for impairments in functional connectivity across subdivisions of the striatum in Parkinson's disease. Hum Brain Mapp. 2015; 36:1278-91.

53. Szewczyk-Krolikowski K, Menke RA, Rolinski M, Duff E, Salimi-Khorshidi G, Filippini N, Zamboni G, Hu MT, Mackay CE. Functional connectivity in the basal ganglia network differentiates PD patients from controls. Neurology. 2014;83:208-14
54. Herz DM, Haagensen BN, Christensen MS, Madsen KH, Rowe JB, Lokkegaard A, Siebner HR. Abnormal dopaminergic modulation of striato-cortical networks underlies levodopa-induced dyskinesias in humans. Brain. 2015; 138:1658-66.

55. Herz DM, Haagensen BN, Nielsen SH, Madsen KH, Lokkegaard A, Siebner HR. Resting-state connectivity predicts levodopa-induced dyskinesias in Parkinson's disease. Mov Disord. 2016;31:521-9.

56. Cerasa A, Donzuso G, Morelli M, Mangone G, Salsone M, Passamonti L, Augimeri A, Arabia G, Quattrone A. The motor inhibition system in Parkinson's disease with levodopa-induced dyskinesias. Mov Disord. 2015;30: 1912-20.

57. Kahan J, Urner M, Moran R, Flandin G, Marreiros A, Mancini L, White M, Thornton J, Yousry T, Zrinzo L, et al. Resting state functional MRI in Parkinson's disease: the impact of deep brain stimulation on 'effective' connectivity. Brain. 2014;137:1130-44.

58. Schweder PM, Joint C, Hansen PC, Green AL, Quaghebeur G, Aziz TZ. Chronic pedunculopontine nucleus stimulation restores functional connectivity. Neuroreport. 2010;21:1065-8.

59. Long D, Wang J, Xuan M, Gu Q, Xu X, Kong D, Zhang M. Automatic classification of early Parkinson's disease with multi-modal MR imaging. PLoS One. 2012;7:e47714.

60. Skidmore FM, Yang M, Baxter L, von Deneen KM, Collingwood J, He G, White K, Korenkevych D, Savenkov A, Heilman KM, et al. Reliability analysis of the resting state can sensitively and specifically identify the presence of Parkinson disease. Neuroimage. 2013;75:249-61.

61. Wu T, Ma Y, Zheng Z, Peng S, Wu X, Eidelberg D, Chan P. Parkinson's disease-related spatial covariance pattern identified with resting-state functional MRI. J Cereb Blood Flow Metab. 2015;35:1764-70.

\section{Submit your next manuscript to BioMed Central and we will help you at every step:}

- We accept pre-submission inquiries

- Our selector tool helps you to find the most relevant journal

- We provide round the clock customer support

- Convenient online submission

- Thorough peer review

- Inclusion in PubMed and all major indexing services

- Maximum visibility for your research

Submit your manuscript at www.biomedcentral.com/submit

) Biomed Central 